\title{
The Soundscape of Becoming Place: Rhythms and Voices of Village des Tanneries
}

\begin{abstract}
Place can be understood as not a fixed geographical location, but as an event that emerges in the encounter between continually transforming material and human elements, social relations and practices; that place is composed of strands of human experience, memory, histories and stories in a particular material setting. This article draws on Amin and Thrift's "ontology of encounter" and Lefebvre's method of rhythmanalysis to explore the complex interactions of geography, social practices and city environment. An "auditory turn" offers ways of thinking about the mobilities, encounters and narratives of an urban neighbourhood that combine and merge to give rise to a soundscape. A turn toward the sensory and auditory offers new paths for analysis in urban geography, mobilities and infrastructure studies.

RÉSUMÉ

La place peut être comprise non comme un lieu géographique fixe, mais comme un événement qui émerge dans la rencontre entre les éléments matériels et humains, les relations sociales et les pratiques sociales; cet endroit est composé de brins de l'expérience humaine, de la mémoire, et des histoires dans un cadre de matériau particulier. Cet article se fonde sur «l'ontologie de la rencontre" d'Amin et Thrift et la méthode de Lefebvre de rythmanalyse pour explorer les interactions complexes de la géographie, des pratiques sociales et de l'environnement de la ville. Un «tour auditif» offre des moyens de réflexion sur les mobilités, les rencontres et les récits d'un quartier urbain combiner et fusionner pour donner naissance à un paysage sonore. Un virage vers le auditif sensoriel et propose de nouvelles voies pour l'analyse en géographie urbaine, les mobilités et les études d'infrastructure.
\end{abstract}

KEYWORDS: soundscape, auditory turn, rhythmanalysis, mobilities, 
infrastructure, urban geography

a

Doreen Massey offers the notion of "throwntogetherness" to understand how place is an event, not a fixed geographical site $(2005,141)$. Place emerges in the encounter between the continuous, ceaseless transformation of material and human elements, social relations and practices; it is composed of strands of human experience, memory, histories and stories in a particular material setting. This becoming of place is positioned within larger topographies that are in turn composed of various political, economic, social and cultural dynamics, and ideologies (Massey 2005). It is within this complex interaction of bodies with a geography, social practices and an urban environment that flows, patterns and rhythms emerge and merge to compose the urban soundscape. A turn toward the sensory, the "auditory turn" offers new paths for analysis in urban geography, mobilities and infrastructure in the everyday life of the city.

Ash Amin and Nigel Thrift suggest that "rhythmanalysis" offers a compelling experience and exploration of the urban environment, but lacks a clear and helpful methodology. Henri Lefebvre's council to "let go, give in and abandon oneself to its duration" (Lefebvre 1996: 219) seems rather vague and ambiguous if one is to embark upon an analysis of place, movement and the built environment of the city. However, Amin and Thrift do not entirely dismiss rhythmanalysis as method, but rather work to assimilate sensory metaphors and methods into an ontology of encounter (2002: 27). They suggest places "are best thought of not so much as enduring sites but as moments of encounter, ${ }^{1}$ not so much as "presents," fixed in space and time, but as variable events; twists and fluxes of interrelation" (2002: 30; italics in the original). As such, place is always a becoming of place; it is found in the temporal-spatial moments of movement and encounter. It is also audible. An "auditory turn," positions sound as a central theoretical approach to inquiries into urban society and culture, infrastructure and mobilities. ${ }^{2}$ It traces the movement and stillness of humans and non-humans in material environments in ways that are inaccessible through visual observation and media. The soundscape becomes the means of contemplating the becoming place in an urban setting, the encounters in and of everyday life. The "Rhythms of Village des Tanneries" is a recorded soundscape of encounters that explores the polyrhythms and characteristics of becoming place in a Montréal inner-city neighbourhood.

The use of sound as a means of thinking about place offers us a way to escape the regime of the gaze, and an opportunity to reveal geographies and places that may not be visible; to hear voices, stories, and vocalities that are silenced or muted. Located in close proximity to Montréal's third busiest highway interchange with the $\mathrm{CN}$ railway tracks demarcating its southern border and the Ville Marie 
Expressway defining its northern limits, Village des Tanneries disputes notions and determinations of "non-place." Augé suggests that "the interchange (where nobody crosses anyone's path)" (1996: 107; italics in the original), is one determined by the rapid circulation of people and goods, and "cannot be defined as relational, or historical, or concerned with identity" (Augé 1996: 78). I stand in the shadow of a massive concrete infrastructure that facilitates the mobilities of over 300,000 vehicles a day, and all around me are the sounds of the historical and relation, the sounds of becoming place.

\section{The Turcot Interchange; an echo of modernity}

The Turcot Interchange is a three-level stacked freeway that connects north-south and west-east bound expressways. It is a critical node in Québec's highway system and has been a feature in the urban landscape of St. Henri since 1967. Beneath the interchange and looking up at the complex criss-crossing of the viaducts one has a feeling similar to that of being in a cathedral; great slabs of concrete suspended in the air, supported by column-like piles and vaulted abutments. It almost inspires a sense of awe. The Turcot Interchange has become an icon of the ambitious and rapid drive to modernize Montréal in the late 1960s. It was one of a number of mega-projects built in the two years prior to Expo '67 and is a manifestation of the contemporaneous discourses of modernity that aspired to achieve efficiency, productivity and a modern aesthetic through urban design.

Standing on Rue St. Jacques overlooking the Turcot Interchange in Montréal one's senses are almost entirely overwhelmed by the roar of traffic, that oceanic lo-fi, universal soundscape of Big Highway. It is at once uncomfortable in its intensity, and intimate in its familiarity. Vehicle traffic and the infrastructure it depends upon are key components of contemporary urban life. It is part of the air we breathe, the surfaces upon we walk, our everyday vistas. However, standing here, in this liminal space, it seems a dispossessed space, a "non-place." It belongs to no one and no one can claim to belong to this space. It doesn't seem to have a history or identity; it is characterized by a desire to move, of reflexive, almost automated encounters between drivers and their vehicles and highway infrastructure. Edward Casey's phenomenological theory of place is one in which perception is the critical entryway into "knowing" a place (1996). ${ }^{3}$ The drivers and passengers on the interchange see little but concrete railings through a windshield, hear only the hum of their cars' engines, the occasional horn or rumble of a truck trailer. One's senses of this interstitial space are reduced to that of an enclosed capsule, a human-car hybrid (Urry 2007), moving at great speeds over an aerial expressway, always on a trajectory to somewhere else - place becomes ambiguous, elusive.

Driving over the Turcot Interchange, one catches glimpses of a city below: neighbourhoods going about their everyday lives beside an immense, concrete highway infrastructure. It almost seems fantastic that people might claim this space as 
place, as home; it's like staking out property on Mars. Yet, it's really not uncommon. People have always found homes and community beneath highways, beside airports, along railway tracks, and ports all over the world. Making place always involves negotiations with the built environment, its multiplicity of flows, patterns of movement and time. Becoming place involves compromises, accommodations and adjustments; it is engaged with continual contestation and affirmation. Therefore, place is not static. It's not a fixed entity that contains the social, but rather it is always coming into being, in a continual state of becoming through "moments of encounter" (Amin and Thrift 2002). Living next to a inner-city highway only seems to emphasize the inherent complexity of a city assemblage. It stages the intricate entanglements of infrastructure and mobilities, politics and economics, technology and the social, histories and imaginaries that come together to make a city, to make a place. It is in the complex interplay of flows and mobilities, social processes and practice, human interactions and the materiality of the environment that place arises and comes into being. The fixity of what Urry calls "moorings" (2007), whether that of an apartment block or highway infrastructure, is in a dialectal relationship with mobilities, flow and rhythms of the city. ${ }^{4}$ The Turcot Interchange is not a barrier or hindrance to making place, it is, in fact, an element of what constitutes place in Village des Tanneries.

\section{Situated knowledge and the senses}

$\mathrm{Yi}-\mathrm{Fu}$ Tuan emphasizes the role of senses, suggesting an "object or place achieves concrete reality when our experience of it is total, that is through all the senses as well as with the active and reflective mind" (1977:18). As such, sensory experiences are an integral part of the observations, the soundscape, and the becoming of place. This project, "a sticky web of language, cognition, sensation, perception and embodiment" (Pink 2009: 27) is representative of my own process where I attempt to amalgamate the different voices, sounds and stories that I experienced in Village des Tanneries into a cohesive narrative. It is not an "objective" scientific study or analysis of a place, but rather my own situated perceptions and understanding. Nor is it an inventory of tempos, durations, sequences and rhythms of the neighbourhood at any given moment; this study is an aural recording of the movements, encounters and narratives of two residents as they go about their day, and the imprint they leave upon the score of the larger neighbourhood soundscape. I address the role of non-human agents, in particular dogs, in producing distinct sounds and rhythms, and what Bissell terms "transversal mobilities," the everyday and chance interactions of people moving around their neighbourhood in contrast to "pointallist mobilities" that define commuter and transport traffic. ${ }^{5}$ Each of these rhythms offer a strain or measure into the larger "polyrhythmic ensemble" of place. ${ }^{6}$ Amin and Thrift's ontology of encounter and Lefebvre's method of rhythmanalysis offer a framework within which to think about and interpret the everyday temporal structures and movement in the organization of timespace, and (re)production of 
connections between the social and built environment.

\section{Suzanne; rhythms of companion species}

Natural and social sounds and rhythms have often been dichotomized, placed on opposite ends of the spectrum; the hi-fi to the lo-fi. But, of course, soundscapes are more complex than that. Most, if not all, natural environments have the pitch, tempo and refrains of a variety of industrial assemblages. These assemblages include natural resource extraction, the aerospace industry, farming and outdoor recreation, forest and park management -- just as cities have birds and trees, wild animals and rivers.

In Montréal you find house finches, chickadees, the common grackle, hawks, pileated woodpeckers, and even a few peregrine falcons saved through a 1980s captive breeding and release program. There are grasshoppers and crickets, mosquitoes, bees and urban beekeepers. All intermingle and mix with the material environment, each with different relations, associations and interactions with human and nonhuman agents. Each species has its flows, movements, interactions, and moments of contact that lend themselves to the sound environment in different frequencies and rhythms. The crickets mingle with oceanic sound of the highways and crows call from treetops while children play in the alleyways. At this moment, I am listening to the sounds of an interspecies interaction familiar and intimate to many urban dwellers - the companion species, the dog and human. Here is the intermingling of what Donna Haraway describes as mixing of "the human and non-human, the organic and technological, carbon and silicon, freedom and structure, history and myth, the rich and the poor, the state and the subject, diversity and depletion, modernity and postmodernity, and nature and culture in unexpected ways" (2007: 4). Haraway offers the figures of the cyborg and companion species as a means of thinking about "a story of biopower and biosociality" (2003: 5), of molecular variances, evolution, symbiogenesis, and "partial connections" (Strathern quoted in Haraway 2003, 25). The companion species is "an emergence process of cohabiting" (2007: 30) in which in "players are neither wholes nor parts" (2007: 8), but rather embody "relations of significant otherness," a history of breeding and the "thickets of technobiopolitics" (2003:10).

I am walking along the banks of the Lachine Canal with a resident of Village des Tanneries. Suzanne has lived in the neighbourhood for about four years with her partner, and has recently begun to walk dogs as a part-time job. A few mornings a week she arrives at the kennel before seven to walk anywhere between 10 and 17 dogs over a two or three hour period. The dog hotel is located on what used to be the Turcot train yards. According to a 1949 Montral Land Use Map, the Meredith Simmon Company, an adhesive manufacturer, stood here with a Terminal building for the railway just across the way. Today, the dog kennel shares the lot with a gym, and, just on the other side of the elevated expressways, there is a recreation centre 
and a series of potholed parking lots. Along the canal are walking and bicycling paths, some benches and trees. This morning, the soundscape is more subdued than usual as it is a Sunday morning.

The birdsong and wind are prominent threads in the soundscape, and from the path we hear the crunch and slide of fine gravel as cyclists and joggers pass. Here we find the intersection of multiple flows and assemblages, each presenting the soundscape with a unique note and tempo. There is an openness to the airspace here, augmented by the vaulted structure of the expressway, and the dispersal of low buildings. This chasmic space is but an echo of its former self as an industrial and railway yard; it is shaped by zoning laws and, I imagine, some measure of reluctance to develop condos so close to the interchange. It has resonances of park and recreation mandates, the complex assemblages that centre around human health ideologies and industries, and the mingling of different species.

Life at the kennel is highly structured. There are schedules to be adhered to, walking and feeding times to be documented and logged, drug prescription protocols to be followed and cleaning and disinfecting standards to be respected. The dogs are walked and fed twice a day, have some running and play time in the gym with other hotel occupants and, for the more privileged, TV time. As an assemblage, the kennel is constitutive of the complex and tangled entities of companion species, urban living and working routines and habits, vacation travel industries, kennel regulation and licensing by-laws, and dog care practices. In The Companion Species Manifesto Haraway employs an analysis of "click and treat", a popular dog training approach to explore ideologies and the "conflicting fantasies we project upon our dogs" (2003: 46). In her imagining of an autre-mondialisation Haraway asserts that ethical relating "is knit from the silk-strong thread of on-going alertness to otherness-in-relation" (2003: 50). That relations, negotiations, love and contestation between species is situated in complex webs of the historical and present, the living and material environment, the global and local, ecology and culture. These interactions, in continual transformation, are co-constitutive of one another and an integral part of making place.

Here, on a slender path on the northwest bank of the Lachine canal, we hear the sounds of the dogs, occasional barking, scratching in the grass, panting and snuffling, the jangle of their collars and tags intermingling with the faint lo-fi of the expressway, the rustle of plastic bags used for poop scoop, the chatter of the dog walkers, bird song and air traffic - organic bodies and technologies, drives and responses, the routine and mundane produce flows and rhythms. This "pulsing, intersection of trajectories and temporalities" (Lefebvre 2004: 17) find active, polyrhythmic relations that perform in the multi-dynamic becoming of place. They sing in harmony and discord the unfolding of a moment in time and space. 


\section{Johanne; transversal and pointillist mobilities}

Children living in Village des Tanneries attend either École Ludger-Duvernay, located near the historical centre of the St. Henri parish, or École St. Zotique, located south of the railway tracks. Those who attend the former school must cross Rue de Courcelle just north of the railway tracks into Square Sainte-Élisabeth. This crossing is attended by Johanne, who has been a crossing-guard for a number of years and calls Village des Tanneries home; she lives, works and has raised her three children here. You will find her here for an hour in the morning, at lunch and after school, greeting, chatting with and ferrying children and adults across the street safely to school or work. In the past few months, most of the traffic on Rue de Courcelle has been construction vehicles as the $\mathrm{CN}$ endeavours to move the tracks by a few feet to accommodate a new train tunnel. On the east side of the street is the square with trees, benches, and a playground; on the west side is the Elpro building. The building originally housed a purse manufacturer, but now an architect firm, a print shop, a software developer, a gym and a dessert and coffee shop reside here. In the morning and evening many of the employees arriving from the east side of St. Henri or the metro station, use Johanne's cross-walk to arrive and leave work. On the corner of Rue de Courcelle and Saint Jacques once stood L'Eglise SaintElisabeth du Portugal. The first church was built in 1810 but, after three fires and two reconstructions, the land was sold to a condo developer in 2008 who built a 143 unit market value condo along with 67 low rent units. The condominium is eight stories high and is significantly taller than neighbouring buildings. It has the effect of enclosing the northeast corner of Village des Tanneries, obstructing view of the elevated Ville-Marie expressway from parts of the village while creating an acoustic sound well. It has also augmented the population of Village des Tanneries by about 250 people. Listening here, at the crosswalk, the lo-fi rumble of highway traffic is constant, sounds of heavy machinery and back-up signals at the railway tracks come at sporadic intervals, commuting and cargo trains pass close, pushing most other sounds away, and amidst all of this is the chatter of Johanne and her charges.

In thinking about how to understand proximity in relation to mobilities, David Bissell offers an alternative to what he terms "the pointillist" model for understanding the co-presence, the forms of receptivity that arise in various modes of movement. $\mathrm{He}$ argues that conventional understandings of the proximities related to mobilities presume the existence of established social networks and that the proximity arises as consequence of "arriving at the right place at the right time" (2013: 355); that a "situated accomplishment" is to be achieved (2013: 355) with the right mobility. Bissell calls for an alternative understanding of proximity, one that allows for multiple forms of receptivity among "near-dwellers" to be conceptualized. Bissell offers a model of "transversal proximity" as means to think about the diverse forms of mobilities and temporal and spatial points of contact among near-dwellers. That pointillist proximity cannot contain the experiential dimensions of everyday mobilities, the transient and momentary proximities that "bubble up" (2013:357) 
in everyday lived experience. Transversal proximities are characterized by the loop and the potential for shifting points of exposure and receptivities. Bissell provides the example of the jogger and dog-walker as engaging in a looping mobility, one that resists a "point-to-point linear trajectory" (2013: 358). The loop offers a sense of multi-dimensional aspects of territory, of the "depths and folds" (2013:359) that arise in everyday mobilities and proximities. With haptic and repetitive everyday mobilities, transversal proximity "changes through repetition" and "saturates space" (2013: 359) and allows for the portrayal of a neighbourhood that is more "fluid, transitional and plastic" (2013:360). As Bissell suggests, these pointillist and transversal proximities are not mutually exclusive, rather they speak and resonate with one another, mingling in the material environment.

Standing here, beneath the maple trees in the square, watching Johanne shuttle children and adults safely across the street and listening to her greet "near-dwellers", chat with dog-walkers, teachers and parents, I am struck by the potential Bissell's concept of "transversal proximities" offers for understanding the experiential, haptic and repetitive rhythms that occupy our everyday soundscapes. The oceanic roar of morning traffic on the expressway and the street level sounds of automobiles on Saint-Jacques, sounds that seem to derive from a pointillist mobility, mingle with those of children looping from home to school and home again, of different people stopping by the square to say hello, sit on the benches, walk their dogs. The close proximity of these different mobilities, the proximities and relations that come into being highlight the co-presence of transversal and pointillist proximities. The presence of the expressway mixed with the local, looping and the experiences of near-dwellers serve as a larger, parallel framework within which to think about the merging and spilling-over of these proximities. Within the pointillist model there is potential for the transversal - the conversations drivers might have with a passenger or on a mobile phone - for the destination-orientation mobilities and subsequent proximities employees or clients of the Elpro building might experience. That within the "restrained geographies of movement around a neighbourhood" (Bissell 2013: 349) encounters are "sustained in ways through intricate and emergent constellations of physical and virtual mobilities" (2013: 353). The experiential dimensions of everyday mobilities are multiple, complex and from their enactment emerge distinct rhythms, keynotes and tempo. Unraveling the tapestry of sound we find threads of the local and global; politics of mobilities; the economics of efficiencies; local stories and memories; urban planning and engineering ideologies. The synthesis of loops speak with one another and find resonance in a built environment that speaks of linear imagination of time and space. The city's infrastructure, the roads and bridges, sidewalks and crosswalks reflect a model of mobility that values efficiency, speed and "situated accomplishment" (Bissell 2013: 355). Yet, within this seemingly static geography come forth forms of receptivity and transversal proximities; contingencies of the prosaic lend themselves to a constellation of sounds and rhythms in wider topographies of space. The loops of everyday lives allow for the 
emergence of what Amin and Thrift suggest is an ontology of encounter (2002: 27) in which the enactment of everyday social relations allow for "becoming place" to emerge. It is the rhythms, tempos, intonations and pitch that weave themselves into the soundscape that we hear this becoming.

The daily rhythms of Suzanne, Johanne and their neighbours make auditive the moments of encounter that allow for the becoming of place. The interactions they have with the built environment and infrastructure, humans and non-humans, mobilities and stillness, complicate our notions of place and non-place while contributing to the polyrhythmic composition of an urban soundscape. The recorded soundscape gives a sense of how we both know and create place through our senses and encounters while staging the complexities of the city assemblage. It is the range and diversity of social practices and people, mobilities and infrastructure, geography and nature that we find the potential of the city, the "unpredictable elements as a result of the co-evolution of problems and solutions" (Amin and Thrift 2002, 4). It is here in this "throwntogetherness" (Massey 2004: 411) of people, infrastructure, nature and mobilities that we find the possibility of improvisation, resourcefulness and a becoming of place.

\section{Notes}

1. Amin and Thrift offer a turn of sorts in sociology through their focus on the conceptualization of encounter and its varied forms and temporal resonances. They understand the city as an intitutionalized practice, a network of systems that allows for connection, extension and novelty. Thus, the city is constituted of "potential and actual entities/associations/togetherness which there is no going beyond to find anything "more real"' and the city "belongs to the nature of a 'being' that it is a potential for every 'becoming' (2002:26-27).

2. Jonathan Sterne in his remarkable book The Audible Past suggests there has been no correlative construct of the conceptualization of visual culture for sound, and works to consider how the auditive might be practiced in theory.

3. Casey argues that epistemologists since Kant have maintained that we know the world through our perceptions and that perceptions take place in space.

Casey suggests instead that "in-placeness" is necessary for those perception to arise, that being in place is both of and result of perceptions (1996).

4. Urry notes that nearly all mobilities "presuppose large-scale immobile infrastructures that make possible the socialities of everyday life." The relatively immobile infrastructural systems from water and gas pipes to satellites and broadcasting towers, intersected with social solidarities, allow for diverse mobilities, including "enforced fixity" and "coerced movement" (2007: 19).

5. Bissell responds to what he believes is a focus on "pointallist" proximity in mobilities studies, that is a focus proximity as destination bound. He advocates for more attention to 
the "transversal proximities that loop "and the movement of everyday life in a neighbourhood (2013: 349).

6. Tim Edensor brings attention to the particular ways in which the mixity of temporal events, of varying regularity, the interweave with one another to shape the diaurnal, weekly, annual experiences of place and create a polyrhythmic ensemble (2013:3).

\section{References}

Amin, Ash, and Nigel Thrift. 2002. Cities: Reimagining the Urban. Cambridge, Massachusetts and Oxford, UK: Polity Press.

Augé, Marc. 1996. Non-Places: An Introduction to Supermodernity. London: Verso.

Bissell, David. 2013. Pointless Mobilities: Rethinking Proximity Through the Loops of Neighbourhood. Mobilities 8(3): 349-67.

Casey, Edward. 1996. How to Get from Space to Place in a Fairly Short Stretch of Time." In Senses of Place, edited by S. Feld and K Basso, 13-52. Santa Fe, New Mexico: School of American Research.

City of Montreal, City of Planning Department. “1949 Montreal Land Use Map.” Montreal, 1949. City of Montreal Archives.

Edensor, Tim. 2010. Introduction: Thinking about Rhythm and Space. In Geographies of Rhythm: Nature, Place, Mobilities and Bodies, edited by Tim Edensor, 1-20. Farnam, U.K.:

Ashgate.

Haraway, Donna. 1988. Situated Knowledges: The Science Question in Feminism and the Privilege of Partial Perspective." Feminist Studies 14(3): 1-65.

—_ The Companion Species Manifesto. 2003. Chicago: Prickly Paradigm Press.

—_. When Species Meet. 2007. Minneapolis: University of Minnesota Press.

Lefebvre, Henri. 1996. Rhythmanalysis: Space, Time and Everyday Life, edited and translated by Elenore Kofman and Elizabeth Lebas. Oxford, U.K., Cambridge, U.S.: Blackwell Publishing.

Massey, Doreen. 2005. For Space. London: Sage.

—_. Space, Place and Gender. 1994. Minneapolis: University of Minnesota Press.

Pink, Sarah. 2009. Doing Sensory Ethnography. Los Angeles and London: Sage.

Tuan, Yi-Fu. 1977. Space and Place: The Perspective of Experience. Minneapolis and London: University of Minnesota Press.

Urry, John. 2007. Mobilities. Cambridge, U.K., Malden, U.S.: Polity Press. 